\title{
Participation in Decision-Making by Staff in Community Mental Health Programs ${ }^{1}$
}

\author{
Cary Cherniss ${ }^{2}$ and Edward Egnatios \\ University of Michigan
}

Staff participation in decision-making was examined in 22 community mental health programs in Michigan. A questionnaire was completed by 164 practitioners employed at least half time. The response rate was $94 \%$. For virtually every work-related decision examined, the practitioners wanted significantly greater participation in decision-making than they currently have. Also, those working in programs where practitioner participation was high reported greater job satisfaction, less role ambiguity, greater use of their skills, better communication among staff, and greater goal clarity and attainability. Practitioner participation was lowest in programs serving more disturbed, less successful populations, such as inpatient, mental retardation, and drug-abuse programs. Paraprofessional practitioners in all programs reported less participation in their jobs than professional practitioners. Finally, practitioners who typically interact more with clients also reported lower levels of participation.

Today, a large proportion of mental health services are delivered in community mental health programs; and a large proportion of practicing mental health specialists now work in these settings. From the point of view of the individual practitioner, this arrangement means that he or she is likely to be one of many other employees working in a relatively large, bureaucratic organization which is part of an even larger and more bureaucratic institution accountable to numerous political groups and interests.

While the ultimate value of the community mental health movement is still a hotly contested question, Sarason (1977) has suggested that one of its ef-

\footnotetext{
${ }^{1}$ The authors wish to thank Seymour B. Sarason who helped secure the necessary financial support for the project. The authors also wish to thank Richard H. Price for his many useful comments and criticisms.

${ }^{2}$ All correspondence should be sent to Dr. Cary Cherniss, Department of Psychology, University of Michigan, 580 Union Drive, Ann Arbor, Michigan 48109.
} 
fects may well be a decrease in the control of individual practitioners over the conditions affecting their work. Previous research in other contexts tends to support this view. For instance, in a study of teacher participation and job attitudes in public schools, Carpenter (1971) found that teachers working in "tall" organizational structures, i.e., those in which there are many hierarchical levels between the bottom and top levels of the organization, reported lower levels of participation in making educational decisions. In community mental health programs, funding by local, state, and federal governments has the effect of increasing the "tallness" of the work organization. More actors and levels must be consulted in making major decisions, and various bureaucratic regulations of each funding agent limit the freedom of action for administrators and staff in any single program. The net effect is a diminished sense of participation in organizational decision-making for any individual member of the organization. Abrahamson (1967) suggested that professionals employed in a bureaucracy usually experience diminished control over their working conditions, and Oppenheimer (1975) has argued that a growing number of professionals employed in mental health and other public institutions are becoming unionized primarily out of a concern about lack of participation in making decisions influencing their work.

If those working in community mental health do in fact feel that they are not sufficiently involved in work-related decision-making, there is reason to believe that this situation will lead to a number of undesirable consequences. First, there now is much research evidence that lack of participation in decision-making is associated with alienation and dissatisfaction with work. Sarata (1972), Marrow, Bowers, and Seashore (1967), and Lawler and Hackman'(1969) all found a significant relationship between measures of employee job satisfaction and level of participation in decision-making. Second, Hall and Schneider (1973) and Harrington and Theis (1968) found significant positive correlations between level of participation and the extent to which workers' skills and abilities were utilized in their jobs. Harrington and Theis also found that higher levels of worker participation were associated with better communication in the organization.

While previous research seems to provide a strong case for the positive effects of participation, one must be cautious about generalizing to the case of community mental health. Much of the previous research has relied on case study methods and limited samples. Most of the better field experimental and correlational research has been conducted in business and industrial settings where the work flow and technology are very different from that found in community mental health and other human service settings. Raskin (1973) has argued that in mental health settings, some workers may want to be told what to do and may be unable to assume responsibility for work-related decisions. There are unusual administrative and organizational problems which make high levels of staff participation both difficult and undesirable. Basic value conflicts among staff, the need to act quickly in times of crisis, and the issue of medical respon- 
sibility are cited by Raskin as formidable obstacles to the sharing of decisionmaking.

The question of staff participation in decision-making is further complicated by the great diversity in client populations, services, staff training and credentials, and other factors in community mental health programs. The extent to which staff want to participate and actually do participate in decision-making may well vary as a function of program, client, and staff characteristics.

In light of the current concern with worker participation in public bureaucracies, the potential for social unrest and labor conflict, the controversy concerning the desirability of worker participation in mental health settings, and unanswered questions about actual, current attitudes and practices regarding staff participation in community mental health, research in this area is needed. The study reported here represented an initial attempt to explore five questions concerning staff participation in community mental health programs:

1. Do community mental health practitioners want to participate more in making work-related decisions? In considering this question, one must recognize that there are a number of different types of decisions made which affect one's work to a greater or lesser degree (e.g., decisions concerning work methods, allocation of resources, hours, hiring and firing, etc.). Workers may be involved in making some of the decisions, but not others; and their preferences for involvement may be similarly differentiated according to decision-making domain.

2. Is greater practitioner participation associated with higher job satisfaction, more opportunity to utilize one's skills, better communication among staff, more adequate goal setting, and less role strain?

3. Do practitioners in certain types of programs consistently enjoy greater participation than those working in other programs? We initially hypothesized that practitioners in "disturbed treatment programs" such as inpatient, drug abuse, and day-treatment settings would experience less participation than practitioners in other programs. This notion was based in part on the observation that line workers and patients in mental hospitals were treated in similar ways (Colarelli \& Siegel, 1966). When the clientele were seen as less responsible, more dependent, and more in need of being led, the staff were seen in much the same way, especially those at the lower levels of the hierarchy.

4. Is professional status, as represented by formal training, educational level, and seniority, associated with higher levels of participation in decisionmaking? More specially, do paraprofessional practitioners participate less in making decisions about their work?

5. Is greater direct contact with clients associated with lower levels of participation? Because most community mental heal th programs are structured in the traditional, "pyramidal" fashion described by Goldenberg (1971), we expected that there would be an inverse relationship between amount of staff contact with clients and amount of staff participation. 


\section{METHOD}

\section{Subjects}

The participants were 164 practitioners and their immediate supervisors working in 22 different community mental health programs situated in three counties in Michigan. The 22 programs were composed of: 10 counseling agencies which might provide consultation and education services in addition to counseling, 5 day-treatment programs serving adults or children, 2 drug-abuse or alcoholism programs, 2 emergency services programs, 1 mental retardation program, 1 inpatient program, and 1 program connected with a probate court. Six programs were located in predominantly urban areas; 3 were located in rural areas; and 13 were predominantly suburban. The sample included 2 psychiatrists, 10 nurses, 55 social workers, 24 psychologists, and 73 nonprofessionals. Educational level ranged from high-school graduate to holder of doctorate degree in medicine or psychology. There were 75 men and 89 women. Work experience ranged from 3 months to over 11 years. All practitioners employed at least half time were asked to participate. Of the 174 practitioners eligible to participate, 164 eventually agreed to do so, a response rate of $94 \%$. Only one program asked to participate refused to do so.

In return for participating, the respondents were promised quick feedback of data for their program compared to others. This feedback was given in written form within 90 days following data collection. Oral feedback was provided in staff meetings held in all programs wishing such feedback.

\section{Instruments}

A written questionnaire was completed by participating staff. The variables examined and the way they were measured in the questionnaire are listed below.

Decision-Making. Degree of involvement in making work-related decisions was measured with an 11-item instrument originally published in Institute for Social Research (1975). The 11 domains of decision-making covered are: (1) deciding when the working day will begin and end; (2) selecting your own supervisor; (3) deciding who is to be hired; (4) deciding who gets pay increases; (5) deciding who is to be laid off, dismissed or fired; (6) deciding who is to be promoted; (7) deciding how well the work should be done; (8) deciding how the work will actually be performed; (9) determining how the work tasks will be divided among people; (10) deciding how resources will be allocated, and (11) determining one's work load. For each domain, respondents are asked to rate on a 5-point scale how much of a say they have now and how much of a say they should have. 
Programatic Factors and Worker Characteristics. The questionnaire also included items providing information concerning type of program respondents worked in, size of the program, average number of hours spent in direct client contact each week, as well as demographic items such as sex, race, and number of years of formal education completed. There also was a section in which respondents indicated areas in which they had formal, supervised training before assuming their present job, including crisis intervention, personal counseling or therapy, mental health consultation, and community organization.

Job Satisfaction. The three scales of the Job Descriptive Index (Smith, Kendall, \& Hulin, 1969) measuring satisfaction with work (18 items), supervision (18 items), and co-workers (18 items) were used to measure these job facets. Measures of satisfaction with pay (one item only) and promotions (one item only) were constructed and included as well.

Role Strain. Seven questions measuring role conflict and ambiguity, published in Institute for Social Research (1975), also were included.

Organizational Functioning. Several other variables which previous research (see above) had suggested might be influenced by level of worker participation were measured with single 5- or 7-point Likert-type items. These included: extent to which staff member is utilizing important skills and abilities in present job assignment; goodness of communication in the agency; clarity of agency goals; attainability of agency goals; and worthiness of agency goals.

\section{Procedure}

Staff filled out the questionnaires in small groups at their agencies during regular staff meetings in the presence of the second author after he explained the nature of the study to them and answered any questions. The average staff member required 40 minutes to complete the survey. (The range was 30 to 60 minutes.)

\section{RESULTS}

\section{Current and Ideal Levels of Participation in Decision-Making}

Table I presents data on current and ideal levels of practitioner participation in decision-making for 11 separate domains. Pairwise $t$ tests, using the statistical procedure advocated in Dixon and Massey (1968, p. 119), were used to test the hypothesis that there was no difference between the current and ideal levels. The results suggested that in every domain, staff would like to participate more in decision-making than presently.

The data in Table I also indicate that participation, as defined in this study, is highly differentiated. The mean scores for current level of partici- 
Table I. Current and Ideal Levels of Staff Participation in 11 DecisionMaking Domains ${ }^{a}$

\begin{tabular}{llcccr}
\hline \multicolumn{1}{c}{ Domain } & $n^{b}$ & $\begin{array}{c}\text { Current } \\
\text { level }\end{array}$ & $\begin{array}{c}\text { Ideal } \\
\text { level }\end{array}$ & $\begin{array}{c}\text { Discrepancy } \\
\text { score }\end{array}$ & $t^{c}$ \\
\hline Select supervisor & 154 & 1.55 & 2.68 & 1.16 & 12.04 \\
Resource allocation & 155 & 2.21 & 3.15 & .94 & 10.33 \\
Promotions & 155 & 1.60 & 2.43 & .83 & 9.61 \\
Pay increases & 156 & 1.40 & 2.15 & .75 & 8.18 \\
Firing, layoffs & 158 & 1.72 & 2.44 & .73 & 8.92 \\
Hours & 162 & 2.58 & 3.24 & .66 & 8.27 \\
Hiring & 160 & 2.22 & 2.88 & .66 & 8.27 \\
Work load & 157 & 3.00 & 3.41 & .41 & 5.68 \\
Division of labor & 157 & 3.00 & 3.39 & .39 & 5.47 \\
Work methods & 156 & 3.46 & 3.77 & .31 & 5.12 \\
Work quality & 155 & 3.34 & 3.63 & .29 & 4.28 \\
Pooled mean & 162 & 2.36 & 3.00 & .64 & 13.22 \\
\hline
\end{tabular}

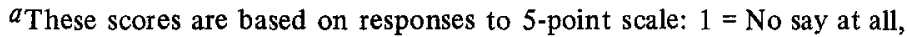
$5=$ I make this decision by myself.

$b$ Refers to number of staff responding to item. Varies with domain due to incomplete responses. Total sample size $=164$.

$c_{\text {Pairwise } t \text { tests based on difference between Current and Ideal scores; }}$ all $p<.0001$.

pation show large differences across the 11 domains. The pairwise $t$ test used in the previous analysis was used to compare the score for each domain with the score for each of the other domains. The analysis revealed that staff participation in the areas of Work Methods and Quality of Work is significantly greater than that for any other individual dimension $(p<.01)$. Level of participation in the areas of Work Load and Division of Labor likewise is significantly greater than participation in deciding Hours. Staff participation in deciding who gets Hired and Allocation of Resources is still lower, and level of participation in deciding Firing and Layoffs, Promotions, Selection of one's own Supervisor, and Pay levels is lowest.

The matrix of intercorrelations (Table II) reveals more clearly the relationships between the different domains of decision-making. The range of magnitudes is considerable, from statistically insignificant correlations of less than .20 to a correlation of .85 .

An analysis on the discrepancy scores created by subtracting the current level of participation from the ideal level revealed a similar picture: size of discrepancies, reflecting amount of staff satisfaction with current levels of decisionmaking, varied considerably across decision-making domains. Specifically, there were smaller discrepancies between real and ideal levels of participation in determining Work Load, Division of Labor, Work Methods, and Quality of Work. Pairwise $t$ tests comparing the discrepancy scores for these domains with those for other domains were all statistically significant $(p<.01)$. Thus, while staff 
Table II. Intercorrelations of Decision-Making Domains $a$

\begin{tabular}{lcccccccccccc}
\hline \multicolumn{1}{c}{ Domain } & HRS & SS & HI & PAY & FL & PR & WL & WQ & WM & DL & RA & $X$ \\
\hline Hours & - & .30 & .38 & .26 & .36 & .40 & .29 & .31 & .21 & .38 & .32 & .61 \\
Select supervisor & & - & .31 & & & & & .24 & & & \\
Hiring & & & - & .52 & .66 & .69 & .33 & .33 & .27 & .51 & .52 & .76 \\
Pay increases & & & & - & .68 & .76 & .28 & .23 & & .42 & .36 & .61 \\
Firing, layoffs & & & & & - & .85 & .36 & .35 & .23 & .56 & .42 & .75 \\
Promotions & & & & & & - & .35 & .34 & .25 & .57 & .53 & .79 \\
Work load & & & & & & & - & .70 & .55 & .44 & .30 & .64 \\
Work quality & & & & & & & & - & .62 & .45 & .33 & .68 \\
Work methods & & & & & & & & & - & .42 & .29 & .58 \\
Division of labor & & & & & & & & & & - & .61 & .76 \\
Resource allocation & & & & & & & & & & & - & .66 \\
Pooled mean & & & & & & & & & & & & - \\
\hline
\end{tabular}

${ }^{a}$ To aid reading and interpretation, only correlations significant beyond the .01 level are shown $(n=154)$.

consistently desire greater participation than they currently experience, their current level of participation and the relative degree of real-ideal discrepancy varies.

Although the data suggest that level of participation in decision-making varies with the domain, we pooled the scores from all the domains for the subsequent analyses reported below. This procedure yields a composite score for each respondent reflecting the average level of participation experienced at work. This composite score is more statistically reliable than the scores for the individual decision domains and simplifies presentation and interpretation of the analyses. Also, as Table II indicates, all domains (with the exception of "selecting one's supervisor") are highly correlated with the pooled score $(r>.60)$. Most of the subsequent analysis also is restricted in that only current level of participation is examined in most instances, while the ideal level and the realideal discrepancy are not included as variables. If either of these other two measures is used in place of current level of participation, identical patterns emerge. (The exceptions will be noted.) Thus, for purposes of economy of presentation we usually use only the score for current level of participation.

\section{Job Satisfaction, Role Strain, and Organizational Functioning}

As predicted, level of staff participation in making work-related decisions was positively correlated with measures of job satisfaction, communication, skill utilization, and goal setting. Also, contrary to what one opponent of participatory decision-making has argued (Raskin, 1973), greater participation was not associated with greater role strain. In the first part of Table III, data pertaining to job satisfaction suggest that staff satisfaction with work, supervision, 
and co-workers was higher in the programs characterized by greater staff participation. Staff satisfaction with salary and promotions was not associated with the general participation score. However, the participation scores for those particular domains were weakly related to reported satisfaction with those domains: The correlation between satisfaction with salary and level of participation in deciding salary levels was $.17(n=159, p<.04)$; and the correlation between the job satisfaction and participation scores for promotions was $19(n=154$, $p<.03$ ).

The results in Table III also suggest that several measures of organizational functioning, including skill utilization, communication, goal clarity, and goal attainablity were more favorable in programs where practitioners participate more in decision-making. One measure not associated with level of participation was perceived goal worthiness. No matter how involved practitioners were in making decisions, they tended to rate high the worthiness of their programs' stated goals. However, the clarity and perceived attainability of those goals was positively associated with level of practitioner participation in decisionmaking.

Only two of the seven items measuring role strain were associated with level of practitioner participation in decision-making. Practitioners employed in programs where participation was high reported that they were more clear about what others expected of them and felt a greater sense of accomplishment in their work compared to other practitioners. Items reflecting role conflict (e.g., "I don't have time to do everything others ask me," and "Different people tell me to do different things") did not discriminate between practitioners in high and low participation programs. Thus, role strain was not found to be higher in community mental health programs where more decision-making was shared with staff; in fact, sense of accomplishment seemed to be higher and role ambiguity seemed to be lower in these programs.

\section{Participation in Disturbed-Treatment Programs}

As predicted, staff working in "disturbed treatment programs" participate less in decision-making than other staff. We initially identified seven different types of programs: those providing general counseling services and mental health consultation, day treatment, emergency services, substance abuse, mental retardation, inpatient programs, and a small program involved with the probate court. A one-way, fixed effects analysis of variance, as described in Dixon and Massey $(1969$, p. 156), was performed on the data summarized in Table IV. The results suggested that the perceived level of participation in decision-making by practitioners did vary with type of program, $F(6,56)=3.40, p<.004$.

Practitioner participation in decision-making was highest in programs providing counseling and consultation services to a relatively intact population, and lowest in programs serving a relatively more disturbed, less successful population (inpatient, mental retardation, and drug abuse). A planned comparison 
Table III. Job Satisfaction, Role Strain, and Measures of Organizational Functioning in "High" and "Low" Participation Programs $a$

\begin{tabular}{|c|c|c|c|}
\hline & \multicolumn{3}{|c|}{$\begin{array}{l}\text { Level of staff participa- } \\
\text { tion in program }\end{array}$} \\
\hline & High & Low & $t$ \\
\hline \multicolumn{4}{|l|}{ Job satisfaction } \\
\hline Work $b$ & $\begin{array}{r}38.09 \\
(75)\end{array}$ & $\begin{array}{r}34.00 \\
(89)\end{array}$ & $2.92 f$ \\
\hline Supervision $b$ & $\begin{array}{r}45.60 \\
(72)\end{array}$ & $\begin{array}{r}40.22 \\
(87)\end{array}$ & $3.88 g$ \\
\hline Co-workers $b$ & $\begin{array}{r}47.95 \\
(75)\end{array}$ & $\begin{array}{r}43.37 \\
(89)\end{array}$ & $3.33 f$ \\
\hline Salary $c$ & $\begin{array}{l}3.87 \\
(75)\end{array}$ & $\begin{array}{l}3.70 \\
(88)\end{array}$ & .60 \\
\hline Promotions $c$ & $\begin{array}{l}3.81 \\
(72)\end{array}$ & $\begin{array}{l}3.50 \\
(86)\end{array}$ & 1.12 \\
\hline \multicolumn{4}{|l|}{ Role strain } \\
\hline Lack of time $c$ & $\begin{array}{l}3.25 \\
(75)\end{array}$ & $\begin{array}{l}3.22 \\
(89)\end{array}$ & .15 \\
\hline Inter-sender conflict $c$ & $\begin{array}{l}2.40 \\
(75)\end{array}$ & $\begin{array}{l}2.60 \\
(88)\end{array}$ & 1.07 \\
\hline $\begin{array}{l}\text { Know what should be } \\
\text { done } c\end{array}$ & $\begin{array}{l}3.64 \\
(75)\end{array}$ & $\begin{array}{l}3.54 \\
(89)\end{array}$ & .61 \\
\hline Too much work $c$ & $\begin{array}{l}2.71 \\
(75)\end{array}$ & $\begin{array}{l}2.89 \\
(88)\end{array}$ & 1.02 \\
\hline Clear what others expect $c$ & $\begin{array}{l}3.73 \\
(75)\end{array}$ & $\begin{array}{l}3.31 \\
(88)\end{array}$ & $2.76 f$ \\
\hline Sense of accomplishment $c$ & $\begin{array}{l}3.53 \\
(75)\end{array}$ & $\begin{array}{l}3.15 \\
(89)\end{array}$ & $2.27^{e}$ \\
\hline Sense of visible impact $c$ & $\begin{array}{l}4.04 \\
(75)\end{array}$ & $\begin{array}{l}3.93 \\
(89)\end{array}$ & .80 \\
\hline \multicolumn{4}{|l|}{ Organizational functioning } \\
\hline Skill utilization $d$ & $\begin{array}{l}4.32 \\
(73)\end{array}$ & $\begin{array}{l}3.74 \\
(88)\end{array}$ & $3.72 g$ \\
\hline Communication $d$ & $\begin{array}{l}5.11 \\
(75)\end{array}$ & $\begin{array}{l}4.32 \\
(88)\end{array}$ & $3.18 f$ \\
\hline Goal clarity $^{d}$ & $\begin{array}{l}5.20 \\
(75)\end{array}$ & $\begin{array}{l}4.63 \\
(89)\end{array}$ & $2.27 e$ \\
\hline Goal attainability $d$ & $\begin{array}{l}5.41 \\
(71)\end{array}$ & $\begin{array}{l}4.95 \\
(86)\end{array}$ & $2.09 e$ \\
\hline Goal worthiness $d$ & $\begin{array}{l}6.04 \\
(74)\end{array}$ & $\begin{array}{l}5.98 \\
(83)\end{array}$ & .39 \\
\hline
\end{tabular}

$a_{\text {Numbers in parentheses refer to number of staff responding. }}$ Total sample size $=164$. The "high" category includes all staff in those 11 programs with the highest average staff decision-making scores. The "low" category includes staff from the lowest 11 programs.

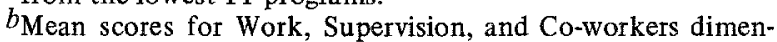
sions are based on total score for respondent on 18-item scales of the Job Description Inventory. Possible range $=0-54$.

$c^{c}$ These scores are based on 1-item, 5 -point scales.

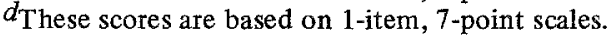

$e_{p}<.05$.

$f_{p}<.01$.

$g_{p}<.001$. 
Table IV. Level of Staff Participation in Decision-Making as Function of Program Type

\begin{tabular}{lrc}
\hline \multicolumn{1}{c}{ Type of program } & $n^{a}$ & $\begin{array}{c}\text { Mean level of } \\
\text { participation } b\end{array}$ \\
\hline General counseling and consultation & $72(10)$ & 2.60 \\
Day treatment & $35(5)$ & 2.43 \\
Emergency services & $18(2)$ & 2.17 \\
Substance abuse & $10(2)$ & 2.05 \\
Probate court & $5(1)$ & 2.04 \\
Mental retardation & $8(1)$ & 1.95 \\
Inpatient & $15(1)$ & 1.83 \\
\hline
\end{tabular}

$a_{\text {Numbers in parentheses refer to number of programs on which }}$ mean is based. Other numbers refer to number of practitioners.

$b$ participation scores were computed by averaging the scores obtained by each staff member on the 11 dimensions of decisionmaking included in the study. The scores refer to a 5-point scale: $1=$ no say at all, $5=$ I make this decision by myself.

between the four disturbed-treatment programs and the other programs was performed in the manner suggested by Hays (1973, p. 587). The results indicated that the inpatient, mental retardation, and drug-abuse staff participated significantly less in making decisions than the other staff, $F(1,161)=4.53, p<.04$.

Disturbed-treatment programs tend to be larger than the less institutional counseling agencies; and staff participation could be related to program size. Thus, the relationship between participation and program type might be artifactual. To test this possibility, we examined the relationship between program size and staff participation in decision-making. Among the 22 programs included in the study, size varied from 1 line practitioner in the smallest to 15 in the largest. (Of course, when clerical and other support staff are counted, the actual, total size of the programs in most cases would be larger.) Our analysis indicated that there was no relationship between number of staff and degree of participation in decision-making. Thus, the lower level of staff participation in the disturbed-treatment programs must have been associated with factors other than program size.

\section{Participation and the Paraprofessional}

All of the characteristics associated with professional status (educational level, formal training, experience in the field, and salary level) were positively associated with level of participation for staff. Practitioners holding a graduate degree $(n=76)$ scored higher on participation in decision-making than those holding a bachelor's degree $(n=58)$; and those who lacked a bachelor's degree $(n=28)$ scored still lower, $F(2,159)=18.73, p<.0001$. 
For training, those staff who had received formal, supervised training in crisis intervention scored higher in participation in decision-making than those lacking this type of training, $t(155)=3.65, p<.001$. The same was true for formal training in psychotherapy or counseling, $t(152)=3.29, p<.002$; and mental health consultation, $t(153)=3.04, p<.003$. For community organization, there was no direct relationship between formal training and participation in decision-making. Thus, only formal, professional training directly related to mental health concerns was reliably associated with level of participation for staff. Finally, amount of experience in mental health work and present salary also were positively correlated with level of participation in decision-making, $r=.31, p<.0001$ and $r=.55, p<.0001$, respectively.

While individual staff characteristics signifying professional status were directly associated with level of participation, other characteristics were not. For instance, there was no significant difference between male and female staff in perceived level of participation.

Taken together, these findings suggest a strong relationship between professional status and degree of control over decisions affecting work. Advanced educational attainment and formal specialized professional training are the traditional, distinguishing personal features of a professional group. However, while professional staff seemed to have greater opportunity to participate in decisions affecting their work, nonprofessionals did not indicate a greater discrepancy between their ideal and current levels of participation. There were no significant differences among educational groups in discrepancy between current level of participation in decision-making and ideal level. While nonprofessionals perceived less personal control over work-related decisions, they seemed to have adjusted downward their expectations accordingly.

\section{Participation and Amount of Client Contact}

As predicted, there was an inverse relationship between amount of client contact and level of participation in decision-making for staff $(r=-.32, p<$ $.001)$. Staff who spend more time working with clients report less participation in decision-making. The effect was even more striking when programs were divided into two groups based on the mean level of participation in decisionmaking for the staff in each program, and then the analysis was performed using the program as the basic unit rather than the staff. Staff in the high-participation programs averaged about 15 hours of client contact weekly, while staff in the low-participation programs averaged about 19 hours of client contact weekly, $t(156)=2.79, p<.01$. Thus, whether the data were analyzed using staff or programs as the unit of analysis, increased client contact seemed to be associated with less staff participation in decision-making. 


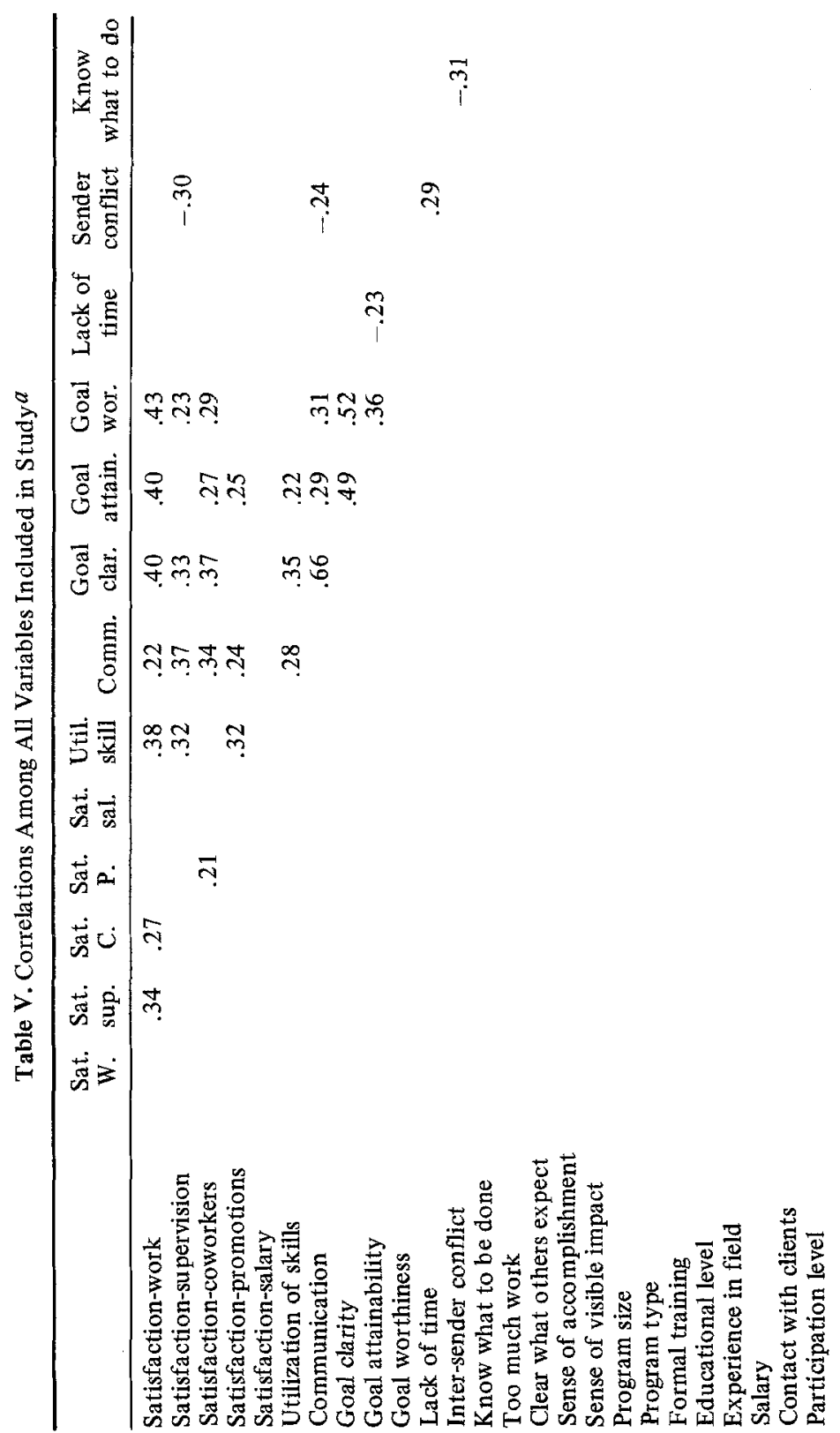




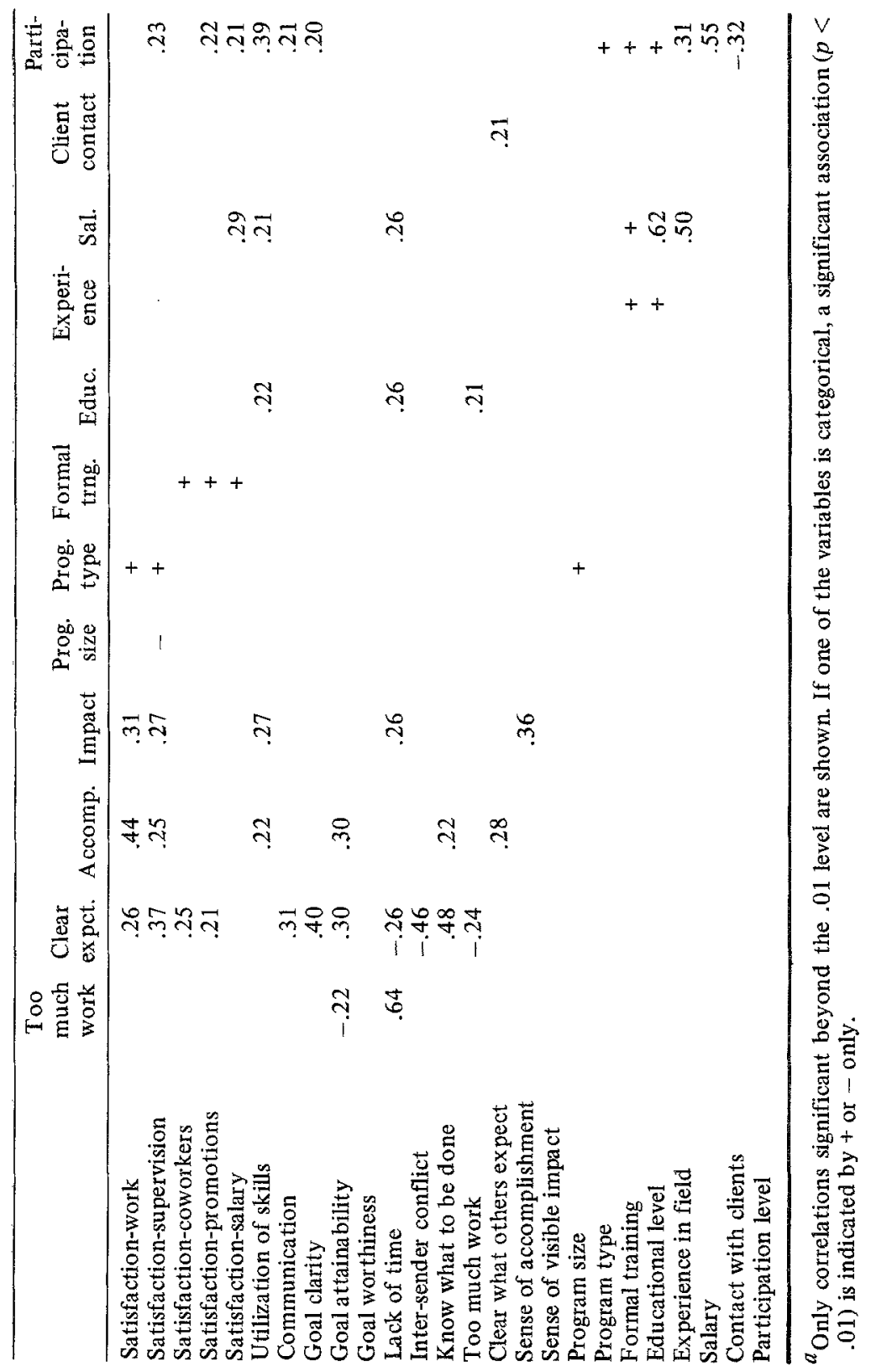




\section{Correlations Among Measures}

The analyses reported above suggested that level of practitioner participation in decision-making is correlated with a number of other variables. But the relationship is not as simple as might be supposed, for many of these other variables also are correlated with one another. Table $\mathrm{V}$ presents the matrix of intercorrelations for all of the analytical variables included in the study. Categorical variables such as program type and whether or not practitioner has received formal training in an area of practice cannot, of course, be included in a correlational analysis. These variables are shown in the matrix, however, with a plus or minus in the appropriate column if they were found to be significantly related to another variable.

Four overlapping clusters of variables seem to emerge from examination of the correlation matrix. The first includes all of the job satisfaction dimensions (except Salary), communication, skill utilization, the three goal-setting variables, and three role-strain variables (clarity of expectations, sense of accomplishment, and sense of visible impact). Participation is correlated with some of the variables in this cluster, but most of these correlations are weak. (Some of the variables found to be associated with participation in analyses presented earlier were not correlated with participation at a level of statistical significance exceeding .01 and thus are not shown as significant correlates in Table V.)

The second cluster of variables includes participation, skill utilization, the "professional status" variables (formal training in mental health related activities, educational level, amount of experience in the field, and salary), and, to a lesser extent, satisfaction with salary and promotions. A third cluster consists of the negative correlation between participation and amount of client contact. The fourth cluster is comprised of the role-strain variables, some of which are not correlated with any variables outside of this cluster.

\section{DISCUSSION}

These data suggest a number of conclusions concerning staff participation in decision-making. First, staff wanted greater participation in making decisions about working hours, assignment of supervisors, hiring, firing, resource allocation, etc. Also, they were more involved in making some decisions than others. It is interesting to note that the four domains in which there is the most perceived involvement in decision-making and the smallest discrepancy between current and ideal levels of involvement ( quality of work, work methods, division of labor, and work load) seem to reflect job autonomy of the sort Abrahamson (1967) and other writers associate with professionalism. The domains in which there is less control concern decisions which affect agency policy and program definition, such as personnel matters and resource allocation. Thus, practitioners 
seem to be relatively more able to make decisions affecting their own individual work load than those affecting the policies and priorities of the institutions in which they work.

Of all the decision-making domains studied, participation in selection of one's supervisor was most at variance with staff ideals. The discrepancy between current and ideal levels of staff participation in making this decision is considerably greater than the discrepancy for any other domain. This finding in part reflects the currently low perceived level of participation. But perhaps the staff's concern with this particular domain also is based on a realistic belief that the type of supervisor one has will greatly affect how much involvement one can have in making many of the other decisions affecting work. While all of the domains may be important determinants of the quality of work life, and staff seem to desire more say in all of them, certain domains seem to be more critical for staff than others. These results suggest that future research should avoid asking global questions about "decision-making" and recognize the highly differentiated and complex nature of decision-making in mental health organizations. While general patterns of staff involvement in decision-making can be discerned, there are many different decision domains. Level and type of involvement in making decisions can vary considerably with the domain.

We found no evidence for the role strain that Raskin (1973) predicted would occur if staff are allowed more participation in decision-making. In fact, one analysis indicated that a major source of role strain (role ambiguity) was slightly greater in programs where staff were less involved in decision-making. Furthermore, we found a positive relationship between communication, goal clarity, and participation in decision-making, suggesting an association between staff participation and indicators of organizational functioning in community mental health programs.

As predicted, staff participation in the community mental health programs studied varied with professional status of the staff, amount of direct contact with clients, and type of program. The finding that staff participation is significantly lower in inpatient, mental retardation, and drug-abuse programs is especially intriguing. These programs differ from the others in a number of respects, any of which could contribute to the observed differences in decisionmaking. For instance, they serve a more "disturbed" and/or "disturbing" client population which may make greater demands on staff and thus discourage sharing of decision-making among staff. Goldenberg (1971) and Colarelli and Siegel (1966) noted that during periods of stress, even a more participative program tends to revert to more authoritarian patterns of decision-making due to an increase in staff dependency needs.

Another factor contributing to lower levels of staff participation in the disturbed-treatment programs could be the structural traditions which prevail in this type of setting. Drug-abuse and inpatient settings may well tend to follow the medical pattern of organizational structure more closely, while many 
mental retardation staff and administrators identify with the field of education. Medical and educational settings tend to be structured in hierarchical and bureaucratic ways (Goldenberg, 1971). Thus, mental heal th programs more closely related to either of these traditions might mirror them in the participation allowed staff.

Whatever the causes, the lower levels of staff participation and autonomy in disturbed-treatment programs should be a source of concern. Assuming that the most gifted and competent practitioners are sought by all mental health programs and thus have some choice in where they choose to work, how can disturbed-treatment programs successfully recruit them? The data suggest that practitioners generally prefer higher levels of participation; and programs high in staff participation tend to have better communication, less role strain, higher job satisfaction, and more effective use of staff skills. In other words, the highparticipation programs in many respects tend to be more desirable places in which to work. Thus, the most gifted practitioners may tend to avoid disturbedtreatment programs in favor of other types of mental health programs eager to hire them, even if these practitioners initially have some commitment to working with a more disturbed and/or needy population. It is difficult enough to work with the severely disturbed or retarded without also having to cope with lower participation, poorer communication, and less clear expectations!

Equally significant is the finding that staff most directly involved in working with the clients tend to be least involved in making decisions affecting their work and, consequently, the delivery of service. This result confirms the fears of observers such as Goldenberg (1971) who argued that such a pattern not only is inherently unjust, but also can produce serious communication problems, poor decisions based on inadequate information and understanding, and other symptoms of "organizational craziness." A recent study of client satisfaction with public bureaucracies (Katz, Gutek, Kahn, \& Barton, 1974) found evidence in a national survey of public attitudes that clients actually tend to be more satisfied with the services received when their workers have greater discretion and control. Thus, the inverse relation between amount of client contact and amount of participation in decision-making might affect outcomes.

The finding that professionals seem to enjoy greater levels of participation in their work settings than do paraprofessionals was not surprising, and some readers may even believe that this situation is right and proper. However, because involvement in decision-making is associated with higher levels of job satisfaction and skill utilization, the lower level of involvement for paraprofessionals may be more detrimental for them and their clients than even they are willing or able to admit. When paraprofessionals have been given greater responsibility and autonomy, they of ten have been able to handle it despite initial reluctance and anxiety on the part of both workers and administrators. For instance, Colarelli and Siegel (1966) demonstrated that psychiatric aides in a men- 
tal hospital could function effectively as the primary therapists for a group of chronic schizophrenics. In their project, an aide had complete authority for decisions regarding her patients. Professional staff on the ward became consultants and advisors to the aides.

In another experiment, Goldenberg (1971) created a residential center for hard core, unemployed, inner-city youth. All of the staff, with the exception of Goldenberg, were indigenous nonprofessionals who had complete authority for the work done with the youth assigned to them. Also, administrative duties were shared among all staff and decisions affecting the center as a whole were made collectively by staff. (The residents also participated in making decisions concerning their center.) At the end of the program's first 6 months of operation, Goldenberg withdrew and all of the staff then were nonprofessionals. There did not seem to be any adverse effects or major problems within the program when nonprofessional staff were allowed a high level of participation.

While the data generally support arguments for giving staff a greater role in making many work-related decisions, one caution should be noted. The present findings are correlational and do not enable one to conclude that greater participation will cause job satisfaction, communication, and other organizational factors to improve. The correlational matrix for all the variables studied did indicate that participation was part of at least three different clusters of variables. In Figure 1, the different variable clusters are arranged schematically in a way consistent with the correlation matrix. According to this proposed model, participation is both a cause and an effect. Professional status, amount of client contact, and adequacy of communication influence the worker's level of participation which, in turn, influences level of skill utilization, adequacy of goal setting, and job satisfaction. (The arrows in Figure 1 indicate the hypothesized directionality of the relationships between variables. Based on the correlational data available, the directionality could be different from what has been proposed.)

If the proposed model is correct, one first could increase a staff member's level of participation by increasing his/her professional status relative to other staff and/or by reducing the amount of client contact. (These changes would increase participation and skill utilization but would not by themselves substantially increase job satisfaction, goal setting, or communication.) One could also increase participation by improving communication, and improved communication also would enhance skill utilization, goal setting, and job satisfaction. Improved communication also would reduce role strain, primarily through making role expectations more clear and reducing conflict in messages received from different role senders.

Although the proposed model is consistent with the findings and helps organize them in a coherent way, there are some possible flaws which should be noted. An important variable is omitted from the model: program type. Level of staff participation and satisfaction with work and supervision were lower in 


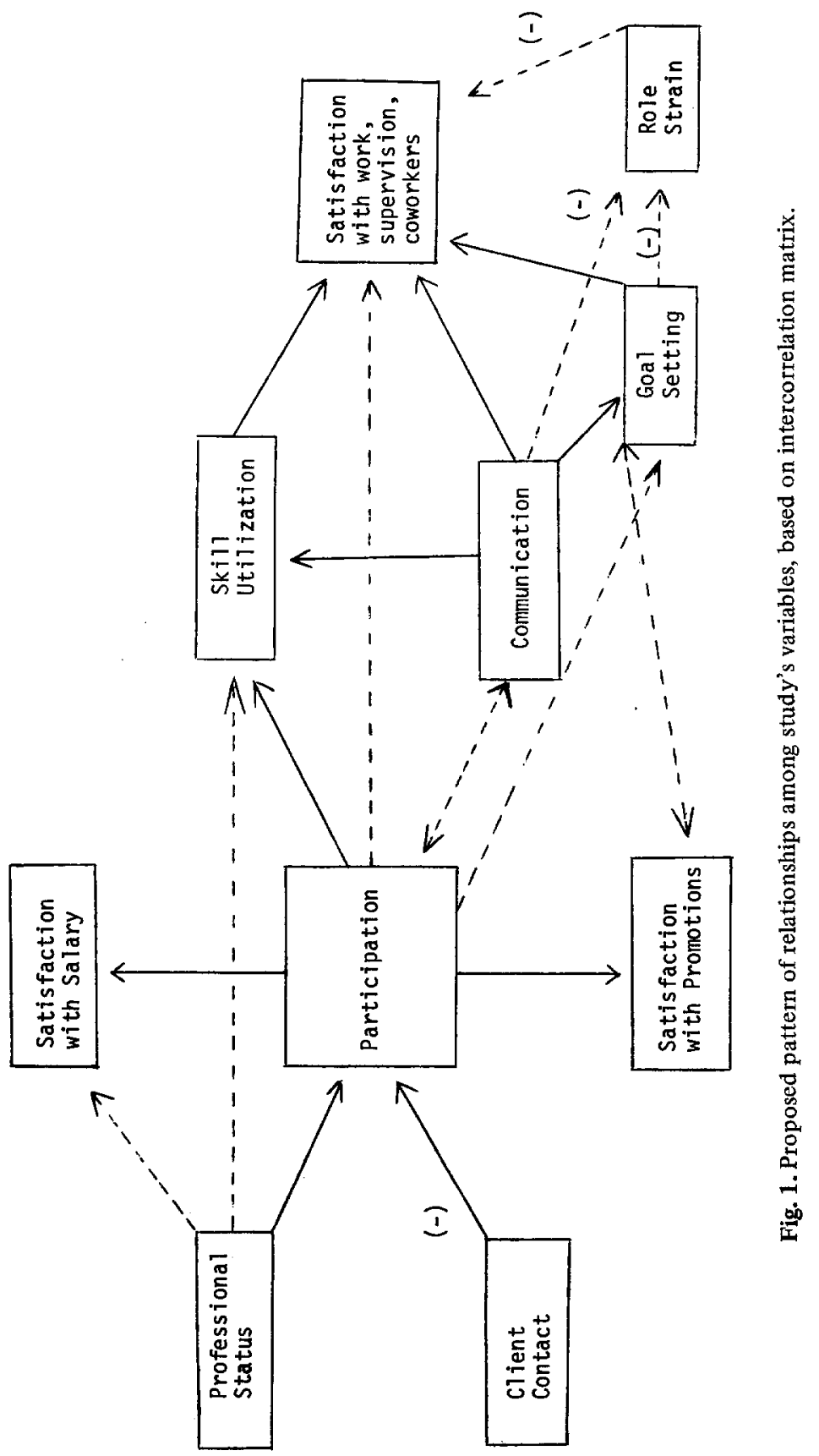


disturbed-treatment programs. One might suppose that there would be more nonprofessionals relative to professionals (thus, lower overall professional status) and greater client contact in these programs as well. However, the data did not support this supposition. Also, a key variable in the model is communication; yet the model does not indicate factors which influence effectiveness of communication. How does commnication effectiveness get to be the way it is in any particular program? How can it be improved? The model provides no answers.

Thus the model presented in Figure 1 does not account for all of the existing data as well as we might wish, and there may be other important variables not even included in this study which should be part of the model. Nevertheless, this model, and the correlational matrix from which it was derived, do reveal that level of staff participation in decision-making is one part of a highly dynamic, complex, interactive system.

Together, the findings do provide a portrait of the staff person working in community mental health today who is least likely to participate in decisionmaking. He or she is a paraprofessional working in a disturbed-treatment program in a role involving extended periods of client contact. This individual, if nothing is done to rectify the situation, will become the "forgotten foot soldier" in the war against mental illness. Originally, community mental health was intended to provide more and better services to the disenfranchised and the more seriously disturbed, those who traditionally were deprived of the services provided by professionals. What seems to have happened, however, is that the staff working in the programs most directly involved with this client population have relatively little influence in making work-related decisions. Those helping the most dispossessed apparently are themselves the most dispossessed among community mental health staff.

However, the current situation is not hopeless. "Job enlargement" and "enrichment" experiments currently are receiving much attention in many work settings. Jobs in many community mental health programs probably could be redesigned to provide greater individual staff participation. The works of Goldenberg and of Colarelli and Siegel, described above, suggest not only that jobs and programs in mental health can be redesigned to increase participation. They also provide models for how it can be done without jeopardizing coordination, supervision, goal attainment, or cohesiveness.

\section{REFERENCES}

Abrahamson, M. The professional in the organization. Chicago: Rand McNally, 1967.

Carpenter, H. H. Formal organizational structural factors and perceived job satisfaction of classroom teachers. Administrative Science Quarterly, 1971, 16, 460-466.

Colarelli, N. O., \& Siegel, S. M. Ward H: An adventure in innovation. New York: Van Nostrand, 1966. 
Dixon, E. J., \& Massey, F. J. Introduction to statistical analysis. New York: McGraw-Hill, 1969.

Goldenberg, I. I. Build me a mountain: Youth, poverty, and the creation of new settings. Cambridge, Mass: MIT Press, 1971.

Hall, D. T., \& Schneider, B. Organizational climates and careers: The work lives of priests. New York: Seminar Press, 1973.

Harrington, H. A., \& Theis, E. C. Institutional factors perceived by baccalaureate graduates as influencing their performance as staff nurses. Nursing Research, 1968, 17, 228-235.

Hays, W. L. Statistics for the social sciences. (2nd ed.). New York: Holt, Rinehart \& Winston, 1973.

Institute for Social Research. Michigan Organizational Assessment Package: Progress report 2. Ann Arbor, Michigan, August, 1975.

Katz, D., Gutek, B., Kahn, R., \& Barton, E. Bureaucratic encounters: A pilot study in the evaluation of government service. Ann Arbor Survey Research Center, Institute of Social Research, 1974.

Lawler, E., \& Hackman, R. J. Impact of employee participation in the development of pay incentive plans: A field experiment. Journal of Applied Psychology, 1969, 53, 467-471.

Marrow, A. J., Bowers, D. A., \& Seashore, S. E. Management by participation. New York: Harper, 1967.

Oppenheimer, M. The unionization of the professional, Social Policy, January/February, $1975,5(5), 34-40$.

Raskin, D. E. Participatory management in psychiatry. American Journal of Psychiatry, $1973,130,219-221$.

Sarason, S. B. Work, aging, and social change. New York: Free Press, 1977.

Sarata, B. P. V. Job satisfaction of individuals working with the mentally retarded. Unpublished doctoral dissertation, Yale University, 1972.

Smith, P. C., Kendall, L. M., \& Hulin, C. L. The measurement of satisfaction in work and retirement. Chicago: Rand McNally, 1969. 